\title{
Translation Project: The Process in Making Good Translation Works
}

\author{
Adam Anshori
}

Islamic University of Yogyakarta

\begin{abstract}
Before we begin a translation work, we must think the process of making it as a whole. We must think all of the aspects which make a good translation. The first thing to do is establishing the project. Here, we will introduce with T4 (text, target, team, and tools). The next step will be Exegesis, Transferring Language and Writing the Draft, Evaluation Step, Result of Revision Draft and Consultation Step.
\end{abstract}

Keywords: translation work, process 


\section{Establishing the project.}

Before someone considers starting a translation project, there are some problems which must be understood clearly by all members which are involved in the project. In English, the problems can be sum into T Four (T4), which are Text, Target, Team, and Tools.

The problem dealing with "Text" is concern with the texts which are going to be translated. The purpose to translate a certain text must be considered wisely. A text is chosen to be translated is because of several reasons. Sometimes the purpose is to inform certain information to other people which speaks different language, or sharing happiness toward the text. A translator must consider the reason in choosing a text which is going to be translated and the potential benefit toward the readers in the translated language.

"Target" refers to audience or the readers of the result of the translation work. Who are expected to read the result of the translation work we make? The form of the language in a translation work is influenced by questions about the dialect, educational level, ages, the mastering of the two languages (SL and TL) and the attitude toward language itself. Whether the translation work is used in schools, in a company, in a place for praying (such as in a mosque) or only at home? The attitude of readers toward the alphabet which are going to be used must be settling up before the translation process begins. There are many good translation works which are rejected because the reader did not like it or they can not read the alphabet being used.

A translation "team" is referring to persons which are involved together in a translation project. If a person (translator) mastered both the source language and the target language, then the whole project can be handled by that person only, meaning that the process of translating into the target language is done by a single person. Though the situation is like that, still the translator must have other personnel in order to discuss and evaluate the work. Mostly in a translation project requires a team, which each personnel will contribute on the translation work in a certain phase of that project. The relationship between each personnel in the team must be settled and clear before the project begins. But in the process the relation can be changed during the project or there is a new factor that becomes new focus.

There are several basic things in every project, and not all of them can be handled only by one person. There are different programs in a translation project which is best if we can decide who will be responsible of it based on the personnel's background and ability. A translation team can consist of 1 ). Co-translators, a person are specialized in the source language and other person in the target language, or 2). a translator who have the ability to handle the problem well either in the source language or the target language, and a consultant, or 3). a partnership commission, which each of the personnel must be responsible in their own specialties. The program which will be developed is depending on who will be involved and qualified to determine the source language meaning. Who is the most qualified person in making a draft in the target language and who has the ability 
or know about the principal in translating? A translation team then can consist of: one or more translator, a consultant, a tester and a corrector, and a technical officer to type and correct the writing style- proof reading. Publisher and distributor are also part of this team. The personnel of the team perhaps need a special training in order to accomplish their duty. This training must be fulfilled before the process of translation project.

"Tools" or utilities are based on the written material in the source language which will be used by the translator to help him/her in the translation process. Besides the document or material which is going to be translated, the other materials consist of dictionary, list of certain words, grammar book, and cultural description both in the source language and the target language. A translation team will need as many information as possible when he/she begins to translate. Every 'tools' must be brought down to the place we translate and prepare our project. For some project, there are maybe lots of materials which are going to be used helping to interpret a text in the source language and to find the match in the target language. For other project, there are maybe only a few materials which are being used, but no matter how many, it must be put there in order to help the translation process. The equipment and the financial support are also considered as tools which are required to fulfill the program effectively.

If the problems of the text, target (audience) and the personnel relation in the transiation team and also the tools which required are available, then the translation project is ready. The project will have steps to be followed, which are: preparation, analysis, transfer, draft, revision of the draft, testing, polishing, and the manuscript preparation for the publisher.

\section{Exégèsis}

Exegesis is a process in finding the meaning of a text which is going to be translated. Exegesis is a step consists of preparation and analysis which have to be done before writing the translation result. The text which is going to be translated must fully understandable. This is a process which happened in the transformation from the source language to the semantic structure, which is contextual meaning.

A translator is better to begin this process by reading the text often and read other supporting material which may be able to help understanding the culture and the language in the target language. When a translator read a text, he/she must find the purpose and the theme of the writing. He/she also needs to make an outline for the text in order to understand the text totally. If all of this has been done, then he/she is ready to analyze each part of the text.

Source text analysis will include resolving a certain meaning, identifying an explicit information, learning the key words, understanding the figurative meaning, knowing when the words is used in a secondary context, when the sentence structure is used in the secondary function, etc. The purpose in exegesis is to determine the context 
which is going to be communicating in the target language. A translator carefully examines a text which is going to be translated and use every tool he/she got, to decide the message content, problems in situational communication, and all factors which are need to be understood in order to make the translation work equivalent.

\section{Transferring Language and Writing the Draft.}

After analyzing the text carefully, a translator then can start writing the draft in each part. The language transfer will make the first draft. In preparing this draft, a translator transfers the source language into the target language. When he/she is in the process of that, he/she must always remember who is his/her target audience. Before the writing of the draft can be done intensively, the key words have to be determined first. Every text has its important words for comprehending the content and to comminicate the theme of the text. The words must be determined first and it's better to check it with the native of the target language.

There are two ways to make transfer and to write the first draft. Some translators will prefer a fast and 'rough' translation so the idea can flow naturally. Then they re-read again the work and tighten up the detail to make sure that there is no wrong information and adding or subtraction of information. In this way, the translation work is more natural. However, there are also translators which prefer to prepare the semantic draft because they believed that the information is accounted for in the text, and then re-write it in order to make it natural by re-write it in the form of idiomatic expression in target language. Both ways are good to be used in making idiomatic translation if it is done carefully.

The first draft need to re-write it very often before the translation team are satisfied and convince that every adjustments had been done properly, no information is wrong or missing, the text is clearly communicate in the target language, and the form which is chosen must be understood by the audience as our target. It is important to remember that every time a translator re-writes his/her draft, he/she always remember his/her audience target. If the translation team has satisfied with the first draft, the next move is to make a copy so the proper evaluation can be done.

\section{Evaluation Step}

There are three purposes in evaluating: precision, clearness and natural.

There are questions we must answer: 1). Is the translation work communicate the same content as in the original-text? 2). Are the audience in which the translation works targeted understanding the meaning of the text clearly? 3). is the form of the work readable and the structure and words is natural? The people who will assist the evaluation must be the native from the target language. 
A translator needs to compare the translation work with the original text during the process of translation to ensure that there are no information which are being added, subtracted or changed. The other personnel in the team can also help. It is better to invite a consultant to check the translation work. The translator needs to ask a few native speakers in the target language to read the translation work and then re-express again what is being communicated in the text. While they are reading, there will be some part of the text which are difficult to be read and understood. Every problem they face and find, it must be recorded in the note. Other ways to check the translation work is by asking someone who has read the text and someone who is read the text by someone else. The questions must be made correctly so it can contain the theme, the writer's purpose, and the relevant facts about the text. Every wrong comprehension must be taken note and crossed check with other readers. It is also necessary to ask someone who never translate but understand enough whether the source language and the target language to re-translate the text from the target language to the source language without knowing the original text. Are the translation work contains the same information as in the original text? If there are some differencés, it must be checked immediately.

The process of evaluating must have a lot of proportion of time and also good efforts. If there are many people who will later used the translation work are involved in the evaluation process, it can create its own sophistication on the translation work if later the work is published.

\section{Result of Revision Draft}

After making an evaluation of the work, then we must make a revision draft based on the input we get. The people, who check our translation work may suggest a lot of changes, explain misunderstanding, etc. The translation team then discusses all of the input and must overwhelm to accept those evaluations and fixes what have been wrong. If there is a key word which is changed, then we must correct the whole text which contains that word and also make sure that the meaning of the text which has that word not changed. If there are some parts which are difficult to read, then those parts must be made easier by adding information so it can be easily understood. How many we make changes is depend on the evaluation result.

\section{Consultation Step}

In many translation projects, a consultant helps the translator. The translator usually hopes that the consultant will be interested in three things: 1): Content, 2). Naturalness, 3). the effect on the audience as the target.

A translator must check his/her translation work material to a trained/ experienced consultant after he/she finishes the translation work. 


\section{Bibliography}

Brislin, Richard W.(1976). Translation Application and Research. New York: Gradener Press:

Newmark, P.(1981). Approaches to Translation. London: Pergamon Press

Newmark, P. (1988). A Textbook of Translation.London: Prentice Hall International

Nida, Eugene and Taber, Ch. (1974). The Theory and Practice of Translation. Leiden : The United Bible Societies. 